\title{
Malaria Morbidity and Mortality Among Patients Admitted at a Tertiary Hospital in Congo DRC and Their Correlates: a Cross-sectional Study
}

Jose Gaby Tshikuka ( $\sim$ jtshikuka@hotmail.com )

National Pedagogical University: Universite Pedagogique Nationale https://orcid.org/0000-0002-70030614

Mgaywa Gilbert Mjungu Damas Magafu

WHO: Organisation mondiale de la Sante

Maurice Kalukul Nsikungu

National Pedagogical University: Universite Pedagogique Nationale

Roy Tapera

University of Botswana

Charleine Inkembila Mupupe

National Pedagogical University: Universidad Pedagogica Nacional

Delphin Mwela Nkola

University of Mbuji Mayi

Jean Kabwe Kalend

National Pedagogical University: Universidad Pedagogica Nacional

Jeanpy Kwete

National Pedagogical University: Universite Pedagogique Nationale

\section{Research Article}

Keywords: Malaria morbidity/mortality, Low socioeconomic patients, higher socioeconomic patients, Congo DRC

Posted Date: March 17th, 2021

DOI: https://doi.org/10.21203/rs.3.rs-299894/v1

License: (c) (i) This work is licensed under a Creative Commons Attribution 4.0 International License.

Read Full License 


\section{Abstract}

Background: In the last two decades, there has been tremendous financial support, political will, and commitment to global malaria elimination focusing on endemic areas. This commitment and support have enabled a few countries to eliminate malaria, while others are making remarkable progress towards elimination. Nevertheless, in the Democratic Republic of the Congo (DRC), the status of Roll Back Malaria (RBM) impact indicators is unclear even though the country is one of the high burden malaria countries in the world. The study aimed to determine malaria morbidity and mortality at Kinshasa Referral General Hospital (KRGH) or the status of RBM impact indicators and factors associated with it.

Methods: The study recruited 870 patients admitted at the KRGH in 2017 and 2018. Patient distribution by cause of admission was analysed. Malaria morbidity, mortality, and case-fatality-rates were estimated. A logistic regression model using malaria morbidity/mortality as the dependent variable was developed.

Results: The morbidity rate was higher in 2018 than in 2017. Mortality and case-fatality-rates were comparable for the two years. Inpatients with low socioeconomic status (SES) were more than twice at risk of malaria morbidity/mortality than inpatients with high SES. The same results were found among city outskirts dwellers vis-a-vis city residents, with city residents faring better.

Conclusion: Malaria morbidity and mortality in DRC were still high at the time of the study, affecting mostly people with low SES. Funding policies in the health sector need to be adjusted for DRC to address the current situation. Access to malaria health care services including drugs for low SES communities should be given priority.

\section{Background}

Malaria killed too many people during World War II. The situation promoted the development of dichlorodiphenyl-trichloroethane (DDT) in the 1940s and fostered the elimination of malaria in many countries. Unfortunately, most of these countries are in the wealthiest parts of the world [1]. Developing countries like those in Africa and Asia were left behind. Eventually, the anopheles mosquito developed resistance to DDT making it difficult for developing countries to benefit from the chemical [2]. To date, many countries in endemic areas are still facing malaria-related calamity, particularly where falciparum malaria transmission is holoendemic or hyperendemic [3]. Other authors [4] think that even in regions where transmission is hypoendemic or mesoendemic, malaria outbreaks happen from time to time, causing massive human and economic loss. This perhaps is attributable to the lack of prolonged exposure to mosquito bites of populations and, therefore, lack of immunity [4]. Malaria prevention and control can be costly and challenging in countries where these four transmission patterns overlap [2], particularly where this is compounded by weak health systems and lack of urbanization like in the Democratic Republic of the Congo (DRC).

For more than two decades now, there has been a strong global political will and momentum to eliminate malaria in the world [5, 6]. Up to 2013, the Global Fund for Malaria, AIDS and Tuberculosis (The Global 
Fund) and many other international organizations were yearly disbursing enough resources to help fight malaria in endemic areas $[7,8]$. Starting in 2014 , investments in malaria prevention and control in highburden countries began to decline [9]. As a result, malaria cases increased globally from 217 million in 2014 to 231 million in 2017 before slightly declining to 228 million in 2018 [9, 10, 11]. Despite this, some countries have improved their Roll Back Malaria (RBM) impact indicators [12] towards malaria elimination in their territories and contributed to the global goal of eliminating malaria. Comprehensive guidelines have been developed to speed up the elimination and eventual eradication process $[6,13]$. Some of the countries like Algeria have been certified malaria-free [11]. Others are remarkably doing well towards elimination, as reflected by their RBM impact indicators [14]. Until now, in the DRC, RBM impact indicator status is still unclear. Although some reports of favourable RBM indicator performance in the DRC are found in the literature [15], most report process indicators [15]. It is important to note that the DRC is one of the high malaria-burden countries globally, second only to Nigeria [11], Hence it is a critical battleground in the war against malaria in the world.

\section{Methods}

The study's objective was to determine malaria morbidity and mortality at Kinshasa Referral General Hospital (KRGH) or to investigate the status of RBM impact indicators, and factors associated with them.

\section{Study design and area}

This was a cross-sectional study of patients admitted at KRGH between January 2017 and December 2018 , a period of two years. The facility was selected because it is the first and biggest referral hospital in the country. The hospital receives clients from all parts of Kinshasa and DRC. It has a capacity of 1,101 beds and an average of 8,468 admissions per year.

KRGH is located in Kinshasa, the capital city of DRC. Kinshasa's planned urban structures were completed in the late seventies when its population was less than 1,200,000. Today, it has an estimated $14,340,000$ inhabitants in an area of $9,965 \mathrm{~km}^{2}$ with only $600 \mathrm{~km}^{2}$ of that urbanized. The upper socioeconomic class of Kinshasa lives in this urban and planned area. Dwellings are modern, roads are paved and access to safe water, electricity and sanitation is relatively better. The outskirts of the city of Kinshasa, mainly inhabited by the lower socioeconomic class, are not urbanized but not planned. Dwellings are substandard and often similar to slum communities [16]. Roads and sanitary systems are in a disrepair state or non-existent, vehicle wrecks and puddles are scattered all over the area, a situation conducive for mosquito breeding and malaria outbreaks.

\section{Sample size, sampling approach and data collection}

The sample size was calculated using a sampling error of 0.05 and a beta level of 0.20 [17]. The proportion of baseline malaria morbidity/mortality among inpatients was assumed to be $20 \%$ [18]. The expected magnitude of association between malaria morbidity/mortality and exposure factors of interest 
(SES and residential area) was set at 1.68 odds ratio. This led to an estimated sample size of 808 , which was increased by $20 \%$. This brought the sample size to 969 participants to allow for any exclusion.

Client hospital registration numbers were used to create the sampling frame. The records included patient files, referral/discharge summaries and mortuary records. Using the computer table of random numbers, 969 patients were randomly selected. Information on the following variables was collected from the patients: age, gender, date of admission, date of discharge, mode of discharge (alive, dead, referred, or escaped), SES and residential area. In addition, information on the top causes of admission at the hospital was also collected. After excluding 99 patients for missing data and discrepancies between different data sources, the study sample size was finally brought to 870 .

\section{Data analysis}

IBM SPSS version 21 (Chicago, IL) was used for analysis of the data. The distribution of inpatients by illness was computed to obtain the profile of major causes of admission at KRGH in 2017 and 2018. Malaria-specific morbidity rate was estimated by dividing the number of inpatients admitted for malaria over the total number of admissions in the same year, times 1000. Malaria-specific mortality rate was calculated by dividing the number of deaths due to malaria over the total number of deaths that occurred in the same year in the hospital, times 1000 . Case fatality rates were calculated by dividing the number of malaria-related deaths over the total number malaria admissions in the same year, times 100. Comparisons between groups/subgroups were made using Chi-square test for trend, Chi-square test with correction of Yates or Fisher exact test. Using malaria morbidity/mortality as the dependent variable and year of admission, age, gender, socioeconomic status, and residential area as independent variables a multivariate logistic regression model was developed to identify predictors of malaria-related morbidity/mortality and to estimate odds ratios and their $95 \%$ confidence intervals. Only variables that achieved a $p<0.09$ significance level were further investigated in the main model. All likely confounders available in the patient records were investigated. Variance inflation factor (VIF) diagnostic was performed for redundancy and multicollinearity of covariates. How well the model fits the data was estimated using the Hosmer-Lemeshow test of goodness of fit.

\section{Results}

Of the 870 inpatients investigated in both 2017 and 2018,260 or $29.9 \%$ had malaria diagnosis. Of the 461 admissions in 2017,119 or $25.8 \%$ were admitted for malaria and of the 409 admission in 2018, 141 or $34.5 \%$ had malaria. Data presented in Table 1 show malaria as the first cause of admission at KRGH in 2017 and 2018, while tuberculosis and HIV/AIDS ranked third and fifth respectively. 
Table 1

Major causes of admission at Kinshasa Referral General Hospital in 2017 and $2018(\mathrm{~N}=870)$

\begin{tabular}{|c|c|c|c|c|c|c|}
\hline \multirow[t]{2}{*}{ Illness } & \multicolumn{2}{|c|}{2017} & \multicolumn{2}{|c|}{2018} & \multicolumn{2}{|c|}{ Total } \\
\hline & $n 1$ & $\%$ & $n 2$ & $\%$ & n3 & $\%$ \\
\hline Malaria & 119 & 25.8 & 141 & 34.5 & 260 & 29.9 \\
\hline ARI & 40 & 8.6 & 42 & 10.4 & 82 & 9.4 \\
\hline TB & 15 & 3.3 & 40 & 9.8 & 55 & 6.3 \\
\hline Diarrhea & 26 & 5.6 & 16 & 4.0 & 42 & 4.8 \\
\hline HIV/AIDS & 17 & 3.6 & 17 & 4.2 & 34 & 3.9 \\
\hline Malnutrition & 19 & 4.0 & 12 & 3.0 & 31 & 3.6 \\
\hline Cancer & 16 & 3.6 & 13 & 3.1 & 29 & 3.3 \\
\hline STI & 7 & 1.5 & 6 & 1.4 & 13 & 1.5 \\
\hline Other diseases & 203 & 44.0 & 122 & 29.6 & 325 & 37.4 \\
\hline Total & 461 & 100 & 409 & 100 & 870 & 100 \\
\hline
\end{tabular}

The malaria morbidity rate in 2018 was significantly $(p<0.05)$ higher than in 2017, while malaria-specific mortality and case fatality rates were comparable between the two years (Table 2).

Table 2

Morbidity, mortality and case-fatality rates attributable to malaria among inpatients at Kinshasa Referral General Hospital by year of admission $(\mathrm{N}=870)$

\begin{tabular}{|llll|}
\hline Admission year & Morbidity & Mortality & CFR \\
\hline & $\mathrm{n}($ rate/1000) & $\mathrm{n}($ rate/1000) & $\mathrm{n}(\%)$ \\
\hline 2017 & $119(258)^{\mathrm{a}}$ & $16(216)^{\mathrm{a}}$ & $16(13.4)^{\mathrm{a}}$ \\
\hline Total $(2017+2018)$ & $141(345)^{\mathrm{b}}$ & $18(277)^{\mathrm{a}}$ & $18(12.7)^{\mathrm{a}}$ \\
\hline $\begin{array}{l}\text { Legend: CFR = case fatality rate, } \mathrm{N}=\text { number of cases, }{ }^{\mathrm{a}, \mathrm{b}}= \\
\text { column indicate significance }(\mathrm{P}<0.05) \text { between values }\end{array}$ & $34(245)$ & $34(13.0)$ \\
\hline
\end{tabular}


In both 2017 and 2018, malaria morbidity rates were similar between participants with high SES and low SES (Table 3). In both years, differences are observed in mortality and case fatality rates; high SES inpatients had significantly $(p<0.05)$ lower mortality and case fatality rates than those with low $S E S$. The same pattern is observed between inpatients in the urban areas and those dwelling in the city outskirts in 2017 and 2018.

Table 3

Morbidity, mortality and case-fatality rates attributable to malaria among inpatients at Kinshasa Referral General Hospital in 2017 and 2018 by SES and by residential area

\begin{tabular}{|c|c|c|c|c|c|c|}
\hline \multirow[t]{2}{*}{ Year } & \multicolumn{3}{|l|}{2017} & \multicolumn{3}{|l|}{2018} \\
\hline & $\begin{array}{l}\text { Morbidity } \\
\text { (rate/1000) }\end{array}$ & $\begin{array}{l}\text { Mortality } \\
\text { (rate/1000) }\end{array}$ & $\begin{array}{l}\text { CFR } \\
(\%)\end{array}$ & $\begin{array}{l}\text { Morbidity } \\
\text { (rate/1000) }\end{array}$ & $\begin{array}{l}\text { Mortality } \\
\text { (rate/1000) }\end{array}$ & $\begin{array}{l}\text { CFR } \\
(\%)\end{array}$ \\
\hline $\begin{array}{l}\text { Socioeconomic } \\
\text { status }\end{array}$ & $57(124)^{a}$ & $5(68)^{a}$ & $\begin{array}{l}5 \\
(4.2)^{\mathrm{a}}\end{array}$ & $68(166)^{a}$ & $6(92)^{a}$ & $\begin{array}{l}6 \\
(4.2)^{a}\end{array}$ \\
\hline \multicolumn{7}{|l|}{ High } \\
\hline Low & $62(134)^{a}$ & $11(148)^{b}$ & $\begin{array}{l}11 \\
(9.2)^{b}\end{array}$ & $73(178)^{a}$ & $12(185)^{b}$ & $\begin{array}{l}12 \\
(8.5)^{b}\end{array}$ \\
\hline Total & $119(258)$ & $16(216)$ & $\begin{array}{l}16 \\
(13.4)\end{array}$ & $141(345)$ & $18(277)$ & $\begin{array}{l}18 \\
(12.7)\end{array}$ \\
\hline \multicolumn{7}{|l|}{ Residential area } \\
\hline Urban & $62(134)^{a}$ & $4(54)^{a}$ & $\begin{array}{l}4 \\
(3.4)^{\mathrm{a}}\end{array}$ & $73(178)^{a}$ & $6(92)^{a}$ & $\begin{array}{l}6 \\
(4.2)^{a}\end{array}$ \\
\hline City outskirts & $57(123)^{a}$ & $12(162)^{b}$ & $\begin{array}{l}12 \\
(10.0)^{b}\end{array}$ & $68(166)^{a}$ & $12(185)^{b}$ & $\begin{array}{l}12 \\
(8.5)^{b}\end{array}$ \\
\hline Total & $119(258)$ & $16(216)$ & $\begin{array}{l}16 \\
(13.4)\end{array}$ & $141(345)$ & $18(277)$ & $\begin{array}{l}18 \\
(12.7)\end{array}$ \\
\hline
\end{tabular}

In the multivariate analysis, there was no significant $(p>0.05)$ difference between the risk of malaria morbidity/mortality between 2017 and 2018 (Table 4). However, patients with low SES had 2.5 times more risk of malaria morbidity/mortality than those with high SES. Similarly, city outskirt dwellers had 2.1 times more risk of malaria morbidity/mortality compared to city residents. 
Predictors of malaria-related hospital morbidity/mortality among inpatients at Kinshasa Referral General Hospital in 2017 and $2018(\mathrm{~N}=870)$

\begin{tabular}{|llllll|}
\hline \multicolumn{6}{|l}{ Dependent variable $=$ Malaria hospital morbidity/mortality } \\
\hline Independent variables & $\mathrm{n}(\%)$ & Unadjusted OR & $95 \% \mathrm{Cl}$ & Adjusted OR & 95\% Cl \\
\hline Year of admission & & & & & \\
\hline 2017 & $461(52.9)$ & 1.0 & - & $1.0^{¥}$ & - \\
\hline 2018 & $409(46.1)$ & $0.7^{*}$ & $0.2-0.9$ & 0.4 & $0.3-3.9$ \\
\hline Age groups (years) & & & & & \\
\hline $5.1-42$ & $436(50.1)$ & $1.0^{*}$ & - & 1.0 & - \\
\hline $0-5$ & $270(31.0)$ & $2.8^{*}$ & $1.3-4.5$ & $1.7 * *$ & $1.5-2.6$ \\
\hline$>42$ & $164(18.8)$ & $1.9^{*}$ & $1.6-3.7$ & 2.1 & $0.8-5.0$ \\
\hline
\end{tabular}

Socioeconomic status

\begin{tabular}{llllll} 
High & $208(23.9)$ & 1.0 & - & 1.0 & - \\
\hline Low & $662(76.1)$ & 1.6 & $0.9-5$ & $2.5^{\star \star}$ & $1.7-4.3$
\end{tabular}

Residential area

\begin{tabular}{llllll} 
Urban (city) & $409(47.0)$ & 1.0 & - & 1.0 & - \\
City outskirts & $461(53.0)$ & $3.1^{*}$ & $1.7-6.2$ & $2.1^{*}$ & $1.2-6.3$ \\
Sex & & & & & \\
Male & $444(51.1)$ & 1.0 & - & 1.0 & - \\
\hline Female & $426(48.9)$ & $1.6^{*}$ & $1.1-7.6$ & 1.4 & $0,9-7.0$
\end{tabular}

Legend: $\mathrm{OR}=$ Odds ratio, $1.0^{\mp}=$ reference group, $\mathrm{Cl}=$ Confidence interval, ${ }^{\star} \mathrm{p}<0.05,{ }^{*} \mathrm{p}<0.001$

\section{Discussion}

This study put malaria on top of all other causes of admission at KRGH in 2018 and 2017. Undoubtedly, this is not the profile that the world would like to see at this particular point in time after so many years of financial and technical support [8] to help eliminate malaria by 2020 and if not, by $2030[6,13,19]$. DRC received from the Global Fund Round 2, 3, 5, 6, 7, 8, 9, and 10 colossal sums totalling the US\$621, 902, 993 to help fight malaria, HIV/AIDS, and TB [8]. The Global Fund support to DRC for years 2017 and 2018 was suspended following fund mismanagement reports [20]. However, other stakeholders [7] continued to bring significant funds and technical support to help the country undertake malaria prevention and 
control measures and, manage all cases of the disease in the population regardless of their SES or residential settings. Nevertheless, findings from this study suggest that this is not happening. The fact that the prevalence of malaria admissions in 2018 is higher than in 2017 indicates that RBM indicators are not declining. Yet, we expected a decline of these indicators rather than a hike or plateau. These results are supported by the multivariate analysis output showing comparable risks of morbidity/mortality between 2017 and 2018. Of more worry in these results are findings showing that low SES inpatients were at more than twice the risk of morbidity/mortality than high SES inpatients and, similarly, city outskirt dwellers having more than twice the risk of morbidity/mortality than city residents. The findings are suggestive of inequities in accessing malaria drugs and/or health care since all these groups are in the same facility. Other likely contributors to the outcome of interest are variables that were not investigated herein, i.e., malnutrition, related comorbidities; further studies should try including them. In fact, at KRGH and many other health care facilities of Kinshasa, inpatients are required to buy their prescription drugs and pay for any needed test and/or services before the assistance. Those who cannot afford the cost are many times left in hospital beds with no assistance. Commonly, these patients end up developing unwanted outcomes from conditions that are normally curable like malaria. Africa Renewal report of December 2016 to March 2017 titled, "Dying from lack of Medicines" [21] described how this is common among African countries.

The negative health impact of low SES and poor neighbourhood residency has been long documented [22], and this is in agreement with what we report herein. People with low SES and those living in the city outskirts of Kinshasa have limited access to health care services owing to their low income [23] and are, therefore, prone to morbidity and mortality compared to their counterparts who have a high SES.

What is inquisitive in this study is the poor access of poor populations to malaria drugs and/or health care services. It put them to 2.5 times more at risk of morbidity/mortality than the upper SES class. This cannot be justified. The financial and logistical support rendered to the DRC for the prevention, control, and management of malaria cases should allow access to malaria drugs and health care in general to even those on the lower end of the SES scale. Inequity in health care access should not exist in the DRC for malaria (TB or HIV) as they are externally funded [7]. The situation may be consequent to the global decline in financial support for malaria, which occurred in 2014/15 [24], or possibly to funds mismanagement. Indeed, a recent report of the Global Funds identified a financial loss from a grant allocated to the DRC malaria program [20]. This may be compounded by the overlap of four malaria transmission patterns in the country, the high burden of malaria and the minimal urbanization in the DRC. Agencies funding the DRC malaria programs, therefore, need to redefine their priorities and grant approaches. Affirmative action, guided by SES and residential settings in the country, should be a priority for malaria elimination in DRC.

This study's limitations include the use of secondary data as the analysis couldn't include other essential variables than those collected by the primary data collectors. Therefore, further studies using primary data are recommended to help to establish the facts better. 


\section{Conclusion}

Malaria morbidity and mortality in DRC were still high at the time of the study, affecting mostly people with low SES. Funding policies in the health sector need to be adjusted for DRC to address the current situation. Access to malaria health care services including drugs for low SES communities should be given priority. We trust that results from this study will ring bells to global malaria elimination stakeholders for decision-making, resource orientation, programming, and strategies that give priority to low SES communities in the DRC.

\section{Abbreviations}

AIDS = Acquired immunodeficiency syndrome

$A R I=$ Acute respiratory infections

CFR $=$ Case fatality rate

DDT = Dichloro-diphenyl-trichloroethane

$\mathrm{Cl}=$ Confidence interval

DRC $=$ The Democratic Republic of the Congo

CFR $=$ Case fatality rate

HIV = Human immunodeficiency virus

KRGH = Kinshasa Referral General Hospital

$\mathrm{OR}=$ Odds ratio

RBM = Rollback Malaria

SES $=$ Socioeconomic status

$\mathrm{STI}=$ sexually transmitted infection

PSI = Population Services International

$\mathrm{TB}=$ Tuberculosis

VIF = Variance inflation factor

WHO $=$ World Health Organization

\section{Declarations}




\section{Ethical Approval and consent to participate}

The School of Public Health Ethical Committees provides general oversight and ethical approval in DRC. This committee does not require a formal submission for ethical approval for research using secondary data. However, Authors' authorization to collect data from KRGH record books was granted to us by the Faculty of Health Sciences of the National Pedagogical University, Kinshasa, DRC. Consent from the hospital management was obtained by confirming that the data only be used for research purpose and no contact be made with patients.

\section{Consent to participate}

Non Applicable: the study was conducted on secondary data set and no contact was made with the participants

\section{Consent for publication}

Non applicable

\section{Data Availability}

Data from which the findings of this study emanate are not publicly available to maintain patient confidentiality. The data include potentially identifying demographic and clinical care information. However, the data can be requested from the corresponding author, who must first get permission from the hospital different departments where the study was conducted before sharing.

\section{Competing of Interests}

The authors have no conflict of interest to declare.

\section{Funding Statement}

The study was financially supported by the National Pedagogical University, Kinshasa, DRC and the University of Mbuji Mayi, Eastern Kasai Province, DRC student research and dissertation funds

\section{Authors' contributions}

The study was designed by J G Tshikuka and C I Mupepe. J G Tshikuka and C I Mupepe supervised data collection at the KRGH and participated in all the stages of this study from proposal preparation to manuscript writing. M G M Damas Magafu, M K Nsikungu and R Tapera participated in reviewing the study proposal, data analysis, and writing the manuscript. D M Nkola, J K Kalend and J K participated in data analysis and manuscript preparation. All the authors contributed to the writing of the manuscript. All the authors read and approved the final manuscript.

\section{Acknowledgments}


We thank the KRGH staff for allowing us to collect the data at their facilities. We are grateful to the Chancellor of the University of Mbuji Mayi, Eastern Kasai Province, DRC, Professor Ghislain Disashi Tumba as well as to the Dean of the Faculty of Health Science, National Pedagogical University of Kinshasa, Professor Jean Luamba for giving us the opportunity to conduct the study.

\section{References}

1. Casida, JE, Quistad, GB. Golden age of insecticide research: past, present, or future? Annu. Rev. Entomol.1998; 43: 1-16.

2. Warrell DA, Gilles HS. Essential malariology, $4^{\text {th }}$ London: Heinemann; 2017.

3. Guerra CA, Gikandi PW, Tatem AJ, Noor AM, Smith DL, Hay SI, et al. The limits and intensity of Plasmodium falciparum transmission: Implications for malaria control and elimination worldwide. PLoS Med. 2008; 5(2): e38. doi:10.1371/journal.pmed.0050038.

4. Hay SI, Guerra CA, Gething PW, Patil AP, Tatem AJ, Noor AM, et al.. A World Malaria Map: Plasmodium falciparum endemicity in 2007. PLOS Medicine. 2009;24;6(3):e1000048. doi: 10.1371/journal.pmed.1000048.

5. WHO. The Abuja Declaration and the plan of action. An extract from the African Summit on Roll Back Malaria, 25 April 2000. 2003;4-5 https://apps.who.int/iris/handle/10665/66391

6. World Health Organization (WHO). World Malaria Report. Geneva: WHO Press; 2017.

7. US CDC. President's Malaria Initiative (PMI): Democratic Republic of the Congo Malaria Operational Plan FY 2018. http://www.pmi.gov/resource-library/mops

8. Global Fund to fight AIDS, Tuberculosis and Malaria, 2010. Available: https://www.theglobalfund.org/media/1336/corporate_2010annual_report_en.pdf. Accessed on 16 February 2021.

9. WHO. World Malaria Report, 2015. Available: https://www.who.int/malaria/publications/worldmalaria-report-2015/report/en/. Accessed on 16 February 2021.

10. WHO. World Malaria Report, 2018. Available: https://www.who.int/malaria/publications/worldmalaria-report-2018/en/. Accessed on 16 February 2021.

11. WHO. Countries and territories certified malaria-free by WHO: Certification of malaria elimination, 1955-2019. Available: https://www.who.int/malaria/areas/elimination/malaria-free-countries/en/. Accessed on 16 February 2021.

12. Roll Back Malaria. Framework for monitoring progress \& evaluating outcomes and impact. Geneva: WHO; 2000. http://www.rbm.who.int/

13. WHO. A framework for malaria elimination. Geneva: WHO Press;; 2017.

14. WHO. The Global Malaria Action Plan: For a malaria-free world, 2020. Available: https://www.rbm.who.int/globalsubsidytaskforce.html. Accessed on 16 February 2021.

15. Lechthaler F, Matthys B, Lechthaler-Felber G, Likwela JL, Mavoko HM, Rika JM, et al. Trends in reported malaria cases and the effects of malaria control in the Democratic Republic of the Congo. 
PLoS One 2019; 14:(7):e0219853. doi: 10.1371/journal.pone.0219853.

16. Drakakis-Smith D. The Third World City. London; Meththuen; 1987.

17. Hennekens $\mathrm{CH}$, Buring JE, Mayrent SL. Epidemiology in medicine. Boston: Little Brown and Company; 1987.

18. Messina JP, Taylor SM, R Meshnick SR, Linke AM, Tshefu AK, et al. Population, behavioural and environmental drivers of malaria prevalence in the Democratic Republic of Congo. Mal J, 2011 ; 10:161. doi: 10.1186/1475-2875-10-161.

19. Dhiman S. Are malaria elimination efforts on the right track? An analysis of gains achieved and challenges ahead. Infect Dis Poverty,2019; 8:1(14). doi: 10.1186/s40249-019-0524-x.

20. Global Fund. Global Fund Grants in the Democratic Republic of Congo Tender manipulation and overpricing in malaria grant, Investigation Report (GF-OIG-19-006) Geneva : WHO ; 2019.

21. Africa Renewal. Dying from lack of medicines. Health and Well-Being, 2017.

22. Chiwuzi. Social class and susceptibility to diseases: a study at the University of Benin Teaching Hospital, Benin City, Nigeria. Health and Hygiene, 1986; 7: 76 -79.

23. World Bank. GDP per Capita (Current US \$) Congo, Dem Rep. World Bank national accounts data, and OECD National Accounts data files. Available: https://data.worldbank.org/indicator/NY.GDP.PCAP.CD?locations=CD. Accessed on 16 February 2021.

24. Shretta R, Zelman B, Birger M L, Haakenstad A, Singh L, Liu Y, Dieleman J. Tracking development assistance and government health expenditures for 35 malaria-eliminating countries. Malar J. 2017; 16(1):125. Doi:10.1186/s12936-017-1890-0. Citation 